\title{
Effects of Cooperative Learning with Dynamic Mathematics Software (DMS) on Learning Inversely Proportional Functions
}

\author{
https://doi.org/10.3991/ijet.v15i20.14339 \\ Kan Kan Chan ${ }^{(\varpi)}$, Yi Cheng Zhou \\ University of Macau, Macao, China \\ kankchan@um. edu.mo
}

\begin{abstract}
Dynamic mathematics software (DMS) has been used in mathematics education for years. However, there is little research which considers integrating the pedagogy of cooperative learning in the DMS environment. The aim of the study is to investigate, using a quasi-experimental research design, the effect of cooperative learning with DMS on students' mathematics achievement. Students in experimental group learned the topic of inversely proportional functions cooperatively using DMS while those in control group had typical didactic instruction. Participants were all ninth-grade students in a Macao private school. Participants were administered an achievement test designed by schoolteachers before and after the instruction. Analysis of students' results on this measure, pre- and post-intervention, showed that the combination of cooperative learning with DMS had a significant influence on students' mathematics achievement.
\end{abstract}

Keywords - Dynamic mathematics software (DMS), cooperative learning, inversely proportional functions, mathematics achievement.

\section{$1 \quad$ Introduction}

As an abstract subject, mathematics education has a long history of using technology to facilitate students' acquisition of mathematical concepts and knowledge [1]. For example, graphic calculator has been used for more than 30 years [2]. Nowadays, technology usually refers to new devices such as hardware and software [3]. For example, tablets and personal computers with appropriate applications were used to help children's comprehension of numbers [4] and problem solving [5] . Interactive whiteboards and its associated software are installed in the classroom to support the wholeclass mathematics lessons [5]. Strategic use of technology is recommended to strength the mathematics instruction altogether [6].

Function is one of the most important topics taught in secondary mathematics education. Students are expected to learn various types of functions such as linear function, proportional, reciprocal, affine function, and quadratic functions etc [7]. However, many students have difficulty understanding and applications of the principles 
underlying these various function; further, grasping such concepts, more often than not, is necessary for acquiring other, more complex mathematical concepts [8] [9]. The efficacy of using technology to facilitate student's learning in these area remains a key question that mathematics teachers are keen to know. Dynamic geometry software (DMS), as a content-specific application for use in mathematics calculations, is one of the tools mathematics teachers use to translate abstract mathematical concepts to more concrete, readily comprehensible forms. The following section presents a literature review of the related work that inspires the current study. Such investigations consider difficulties students encounter when learning mathematical functions; dynamic geometry software and its potential and challenges in mathematics instruction; the value of cooperative learning in supporting students' learning. In light of the findings thus for derived, we also discuss the value and contributions of the current study.

\subsection{Students' difficulty of learning functions}

Even though function is an important topic in secondary mathematics, students are not very proficient in their use. Learning mathematical functions requires students to gain knowledge and fluency in a range of external representations of mathematical concepts (including algebraic, graphical, tabular representation). However, students often encounter difficulties and acquire misconceptions in endeavoring to learn functions [8] [9]. The dual nature of function as object and operation might generate confusion to students [10]. The intrinsic ambiguities in the mathematical notation is another challenge. In terms of instruction, the lack of mathematical tasks at schools make students hard to gain a solid understanding of function [11]. Students could not easily make flexible representational choices, as is necessary to solve a mathematical problem [12]. They cannot accurately link representations of proportional and various kinds of inversely proportional functions, positive slope affine functions and negative slope affine functions [13]. Since these functions are conceptually related, students often associate an inversely proportional function to representations of proportional functions or affine function with a negative slope. When function value is displayed in a table, students can verify if these data fit a given function. However, they can have problems in connecting a formula with its graph and vice versa. Their understanding of functions is mainly on linear and proportional functions. They tend to select or produce a linear graph to non-proportional model. This phenomenon has been characterized as an overreliance on linearity and proportionality [14]. Therefore, students' understanding of functions is often incomplete and confusing, even after graduation from high school [15].

\subsection{Dynamic geometry software}

Dynamic mathematics software (DMS) has been used in mathematics education for years. DMS, as a content-specific software handling mathematics-related operations, includes various representations of mathematical concepts in a platform [16]. A change in formula of a function would alter its corresponding graphical representation 
[17]. This context provides hand-on practice and concrete experience for students endeavoring to learn mathematics [18]. Besides, the preserved properties of mathematical concepts remain constant in dynamic transformations; this makes the job of teachers significantly easier and more productive [19]. Learning condition involving manipulations of properties of geometric objects with DMS might reduce demands on a learner's working memory capacity [20]. Therefore, learning with DMS can improve students' mathematics achievement [21] [22] and learning motivation [23] [24].

Despite the potential of DMS to facilitate mathematics education, there are challenges that are encountered with its integration. For instance, students may neglect the mathematical concepts to be learned and focus exclusively on solutions. In another regard, they may experience cognitive overload [25]. Teaching with DMS also requires a different emphasis in teaching strategy [26].

\subsection{Cooperative learning as teaching strategy}

Cooperative learning may help students overcome the challenges mentioned in previous section. This approach has widely been studied and adopted in educational contexts. Students in cooperative learning environments generally have higher achievement and self-esteem than those studying in individualistic and competitive environments [27]. Slavin [28] suggested using the Student Teams-Achievement Divisions (STAD) as the cooperative learning method wherein students are grouped heterogeneously to help each other in the learning process. Cooperative learning has been found to improve students' mathematics achievement, attitude and transfer of knowledge when it is implemented effectively [28] [29] [30]. Therefore, cooperative learning has been extended to technology environment e.g. interactive whiteboard [31], web-based environment [32] and DMS [33]. Since DMS can provide a shared working space with instant feedback, integrating DMS into cooperative learning programs may provide opportunity for students to discuss together and help one another to solve the issue of cognitive overload and focus on the mathematical concepts. Zengin and Tatar [33] found that cooperative learning with DMS facilitated students in learning hard mathematical concepts.

\section{$1.4 \quad$ Present study}

Although DMS has been studied for many years, there are few a meta-analysis or systematic reviews of studies investigating its effect in mathematics instruction [21]. Only one study has been identified with the instructional approach of cooperative learning with DMS. Zengin and Tatar [33] applied the cooperative learning model, supported with DMS, to teach a group of 61 high school students about the quadratic functions and sequences topics. The results showed that students in the treatment group had better performance on a mathematics achievement test than the control group; as well, the students liked the new learning model using DMS. As the study of Zengin and Tatar [33] was a single group pre-test post-test design, it is necessary to verify their findings. 
This study fills the research gap existing in which there are few empirically based studies of the field of DMS and cooperative learning. The research integrated the cooperative learning model with DMS, with the intention of correcting students' overreliance on linearity and proportionality [34]. DMS provides a link among visual, tabular and formula-based representations of function to students. Overall, students showed an interest in studying within this concrete, visualized and dynamic environment. In the STAD cooperative learning model, students studying in a heterogeneous group had the potential to make weaker students perceive less difficulty in understanding the topic. They also were able to challenge one another's understanding and improve the communication and collaborative skills. As the research design of the previous study was a single group pre-test post-test design, there exists many threats to the validity of the findings [35]. Therefore, this study investigates the effect of a cooperative learning model with DMS on students' mathematics achievement using a quasi-experimental research design. The following research questions guided the investigation:

1. What is the students' achievement on the learning of inversely proportional function with the cooperative learning model with DMS?

2. Is there any difference between the effects of instruction on mathematics achievement between the treatment and control group?

3. Is there any difference between the attitudes toward mathematics of treatment group before and after the intervention?

4. What is students' perception of cooperative learning model?

With reference to the literature discussed above, the current study hypothesized that students in the treatment group of cooperative learning combined with DMS would gain a higher score on the mathematics achievement test of inversely proportional function. It was also hypothesized that they would have a better attitude towards the new approach of learning.

\section{$2 \quad$ Methodology}

\subsection{Research design}

This study followed a pre-test and post-test quasi-experimental design. Before the intervention, participants were evaluated for their pre-requisite knowledge of inversely proportional function and their attitudes towards mathematics. After that, they were given a series of four lessons across five days to learn inversely proportional function. Students in the control group learned this material in traditional manner, namely didactic instruction. Students in treatment group learned cooperatively using DMS. After instruction, students' knowledge of inversely proportional functions and their attitudes towards mathematics were measured. Students' perception of the cooperative learning was also collected. 


\subsection{Participants}

The principal of a Macao private school was purposefully contacted because the school has been using DMS in mathematics instruction for a number of years. After the approval of the Principal to conduct the study, the instructional design of DMS integrated with cooperative learning, was sent to the schoolteacher. Researchers followed the ethical principles of confidentiality and anonymous use of data. Participants were two classes of ninth-grade students in that school. According to the school information, the two classes were of similar performance level. They were 52 students in two classes. The number of male and female students were 34 and 18 respectively. The treatment group had 16 boys and 10 girls, while the control group had 18 boys and 8 girls. Each classroom in the school had a projector with screen and computer. Mathematic teachers in that school had been using a self-developed DMS tool, DM_LAB (Dynamic Mathematics Laboratory). Therefore, students were familiar with DMS (they had some experience of using DM_LAB in grade 7 and 8). Mathematics teachers usually demonstrate mathematical concepts with DMS in class for students to observe. Teachers sometimes provide opportunities for students to manipulate mathematical objects in the computer laboratory. DM_LAB was developed by the former president of Macao Computer Society. DM_LAB is designed for users to learn mathematics by exploration [36]. It is a virtual laboratory where students can explore mathematical concepts in the area of geometry, algebra and calculus. A screen shot of DM-LAB is provided in Figure 1.

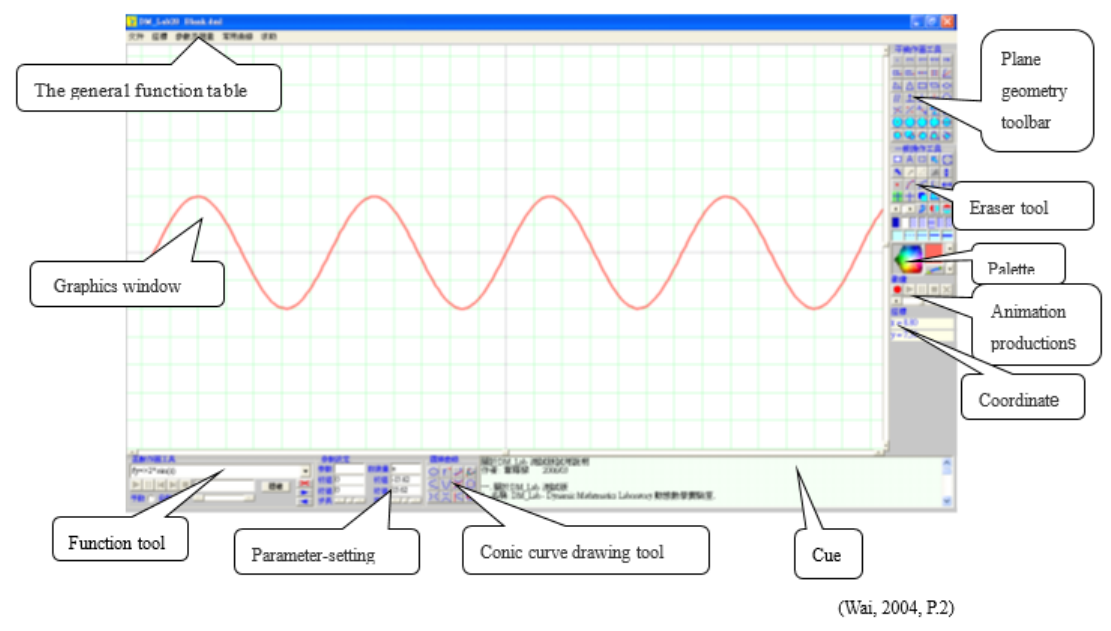

Fig. 1. User interface of DM-LAB.

\subsection{Learning activities of treatment and control group}

In each lesson, the treatment group followed the flow of:

1) Whole class instruction by the teacher 
2) Discussion among group members

3) Individual quiz

4) Group review

The time allocated for the four sessions was 15 minutes, 18 minutes 5 minutes and 2 minutes respectively. First, teacher aroused students' interest in the topic and provided necessary information on the blackboard. This was to ensure that students understand the content and were ready for group discussion. During group discussion, members asked questions, made suggestions, and solved the problem with the help of DM_LAB and a given worksheet. The group leader had to sum up ideas provided by the group members. In individual quiz session, students were given 5 short questions to answer. The purpose of the quiz was to examine if students achieve the learning objective or not. Group members had to check if their work was done appropriately or not. Finally, the group review session allowed group members to know the performance of each group by adding their individual score. The group with the highest score would be publicly recognized in class by the teacher so as to motivate students working in groups. Therefore, the treatment group always studies in the group with DM-LAB.

For the control group, the teacher would explain the concept on blackboard to the whole class. Students learned the graphical property of inversely proportional function and plotted its graphical representation in a worksheet by following the teacher's instruction. Students in the control group mainly listened to and observed teacher's instruction. They had only one lesson to work with DM_LAB individually.

\subsection{Data collection tools}

Mathematics achievement test - The purpose of the first mathematics achievement test was to measure students' prerequisite knowledge of inversely proportional function. Proportional functions are taught before inversely proportional functions; it is necessary to know whether there exists a difference of proficiency of proportional functions. Therefore 19 items were designed by the school mathematics teachers to measure students' understanding of the different representation of linear proportional functions. Appendix 1 lists the sample test items of the pre-test.

The purpose of the post-test was to examine the effect of instruction on two groups' mastery of inversely proportional functions. Another set of 19 items were designed by the school mathematics teachers to measure students' understanding of the different representation of inversely proportional functions. Appendix 2 lists the sample test items of post-test.

Attitudes towards mathematics - The Chinese version of the Fennema-Sherman (1977) mathematics attitude scale [37] was used as a measure of the attitude towards mathematics. We adopted 5 constructs of the whole questionnaire, including students' perception of mathematics on the construct of success, confidence, anxiety, motivation and usefulness. The questionnaire has 60 questions and each dimension contains 12 questions. The reliability coefficient of the 5 constructs are all between 0.6 and 0.8 in the five dimensions. 
Perception of cooperative learning - Students in treatment group were given a short survey to seek their perception of cooperative learning with DMS. The survey consisted of 5 statements which were in the format of a Likert-type scale with the following anchors: 1 strongly disagree, 2 disagree, 3 neutral, 4 agree, and 5 strongly agree. The survey measured students' behaviors during cooperative learning in 5 aspects: expression, listening, attention, communication and sharing [38].

\subsection{Data analysis}

Descriptive statistics of students' achievement scores in pre-test and post-test were explored. The Shapiro Wilk test was used to check if the collected data came from a normally distributed population. Results showed that the normality assumption was fulfilled except for the pre-test score of the control group. Outliers were identified by checking the Q-Q plot. After excluding the outliers, the Shapiro-Wilk test of the pretest score of the control group was 0.148 . All the data met the assumption of normality. Therefore, collected data were analyzed by independent sample t-test and paired sample t-test. The value of 0.05 is set as the minimum significance level in this research. SPSS software is utilized to obtain the statistic which is needed for investigation.

\section{Results}

The descriptive statistics of the pre-test and post-test results of students in two different instructional methods with respect to the mathematics achievements are summarized in Table 1. The mean score and standard deviation of students in two different instructional approaches are listed. In order to discover the difference between the two groups, a t-test was calculated. The pre-test mean score of the control group was not significantly higher than the treatment group, where $p$ is 0.192 . This means that the two groups based on the pre-test score of linear proportional functions were equivalent. The pre-test results verified schoolteachers' claim of the two groups were similar in performance. Analysis of students' test papers showed that they were able to draw a graphical representation of a mathematical problem and provide an algebraic formula. However, they were weak in formulating the algebraic expression when its graphical representation is given. Students in control group had similar understanding in the concept of linear proportional functions and had similar difficulties.

Table 1. Independent sample $t$ test of students in two instructional approaches

\begin{tabular}{|l|c|c|c|c|c|}
\hline \multicolumn{1}{|c|}{ Group } & \multicolumn{2}{c|}{ Control } & \multicolumn{2}{c|}{ Treatment } & p \\
\hline & Mean & SD & Mean & SD & \\
\hline Pre-test & 5.96 & 3.22 & 4.92 & 2.13 & 0.192 \\
\hline Post-test & 6.71 & 2.95 & 6.54 & 2.21 & 0.818 \\
\hline
\end{tabular}

After instruction of inversely proportional instruction, the post-test scores of the two groups were not significantly different with $p=0.214$, even though the mean 
score of the control group is still higher. The results show that there was no significant difference between the two groups in terms of inversely proportional function. This implies that these two approaches of instruction both help students learn. Analysis of students' responses in the post-test showed that students were able to answer items related to basic properties of inversely proportional function. However, students were weak in translating the graphical representation to the algebraic representation.

\subsection{Significant learning gains of the instructional approach of cooperative learning with DMS}

The instructional effect of two approaches of instruction was calculated using paired sample t-test as shown in Table 2. The change in score of the control group and the treatment group was 0.75 and 1.61, respectively. The analysis results given in Table 2 showed that there was no significant difference in the post-test score of the control group $(\mathrm{M}=6.71, \mathrm{SD}=2.95)$ compared to the pre-test $[\mathrm{M}=5.96, \mathrm{SD}=3.22$, $\mathrm{t}(23)=0.99, \mathrm{p}=0.332]$. These results suggest that the typical instruction of teacher demonstrated DMS did not significantly increase student achievement in inversely proportional functions. For the treatment group, there was a significant difference in the post-test score $(\mathrm{M}=6.54, \mathrm{SD}=2.21)$ compared to the pre-test $[\mathrm{M}=4.92, \mathrm{SD}=2.13$, $\mathrm{t}(25)=3.254, \mathrm{p}=0.003]$. These results suggest that the instruction of cooperative learning with DMS significantly increased student achievement in inversely proportional functions. Hence, it was suggested that the instructional approach of cooperative learning with DMS enhanced students' learning of inversely proportional functions.

Table 2. Paired sample $t$ test results of students' pre-test and post-test scores

\begin{tabular}{|l|c|c|c|c|c|c|c|}
\hline \multirow{2}{*}{ Group } & \multicolumn{2}{|c|}{ Pre-test } & \multicolumn{2}{c|}{ Post-test } & \multirow{2}{*}{ r } & \multirow{2}{*}{ t } & p \\
\cline { 2 - 8 } & Mean & SD & Mean & SD & & .990 & 0.332 \\
\hline Control & 5.96 & 3.22 & 6.71 & 2.95 & .282 & $.990 .003^{*}$ \\
\hline Treatment & 4.92 & 2.13 & 6.54 & 2.21 & .322 & 3.25 & 0.25 \\
\hline
\end{tabular}

$* \mathrm{p}<.05$.

\subsection{No significant differences in the learning gains between two instructional approaches}

To compare the differences in the learning gain of the two instructional approaches, we first calculated the learning gains of each group by subtracting the pre-test scores from the post-test scores. Then, an independent-sample t test was conducted to compare the two learning gains, as shown in Table 3. There were no significant difference $(\mathrm{p}=0.337)$ in the learning gains of the treatment group $(\mathrm{M}=1.61, \mathrm{SD}=2.53)$ and the control group $(\mathrm{M}=0.75, \mathrm{SD}=3.7, \mathrm{t}(48), \mathrm{p}>.05)$. 
Table 3. Independent sample $t$ test results of students' learning gain

\begin{tabular}{|l|c|c|c|c|c|}
\hline & \multicolumn{2}{|c|}{ Control } & \multicolumn{2}{c|}{ Treatment } & $\mathrm{p}$ \\
\hline & Mean & SD & Mean & SD & \\
\hline Learning Gain & 0.75 & 3.70 & 1.61 & 2.53 & 0.337 \\
\hline
\end{tabular}

\subsection{No significant changes of students' attitudes towards mathematics after instruction}

Students' attitudes towards mathematics before and after the treatment in 5 dimensions was provided in Table 4. Even though there are minor changes in various constructs of the attitudes towards mathematics, the changes are not statistically significant. This implies that students have neither negative nor positive attitude towards the new model of learning model. Their attitude towards mathematics might not be changed in a short period of instructional intervention.

Table 4. Students' attitudes towards mathematics before and after instruction

\begin{tabular}{|l|c|c|c|c|c|c|}
\hline Construct & \multicolumn{2}{|c|}{ Pre-test } & \multicolumn{2}{c|}{ Post-test } & Change & p \\
\hline & Mean & SD & Mean & SD & & \\
\hline Success & 39.65 & 6.24 & 38 & 5.07 & -1.65 & 0.29 \\
\hline Confidence & 35.5 & 10.01 & 35.53 & 8.83 & 0.03 & 0.98 \\
\hline Motivation & 37.65 & 7.09 & 35.23 & 7.85 & -2.42 & 0.24 \\
\hline Usefulness & 38.19 & 7.64 & 37.46 & 5.65 & -0.73 & 0.69 \\
\hline Anxiety & 35.92 & 9.14 & 36.61 & 8.38 & 0.69 & 0.77 \\
\hline
\end{tabular}

\subsection{Students' perception on cooperative learning}

Descriptive statistics of students' perception on cooperative learning is listed in Table 5. The mean score of 5 constructs of cooperative learning is above 3 . The collected data suggests that they would listen and pay attention to groupmates' ideas. They would share their own ideas with others and discuss among group members. Data seem to imply that majority of students do not have negative perception of integrating DMS with cooperative learning. They are practicing essential elements of collaborative skills.

Table 5. Descriptive statistics of students' perception on cooperative learning

\begin{tabular}{|l|c|c|}
\hline \multicolumn{1}{|c|}{ Construct } & Mean & SD \\
\hline Expression & 3.57 & 0.88 \\
\hline Listening & 3.75 & 0.84 \\
\hline Communication & 3.71 & 0.89 \\
\hline Attention & 3.68 & 0.90 \\
\hline Sharing & 3.72 & 0.88 \\
\hline
\end{tabular}




\section{Discussion}

This study investigated the effects of integrating DMS with cooperative learning on students' learning of inversely proportional functions. Analysis of collected data suggests that the instructional approach of DMS, integrated with cooperative learning, is effective for increasing student' achievement in inversely proportional functions. This results confirms the findings of Zengin and Tatar [33], who used DMS with cooperative learning to support students' learning of quadratic functions. This study confirms that the instructional method of cooperative learning with DMS helps students learn difficult concepts. It also extends the work of Zengin and Tatar [33] with a better research design.

Despite the significance learning gain of the treatment group, a comparison of the effect of treatment group to that of control group showed that there were no significant differences between the two instructional approaches. This findings contrasts with the large effect size of instruction using DMS based on a meta-analysis of quasiexperimental studies located in the literature [19] [30]. Students in the treatment group may not adapt to the pedagogy of cooperative learning (as they are used to the instruction delivered by the teacher). Students may not know how to cooperate among themselves to tackle the mathematic task with a short duration of 4 lessons. More time is needed for students to adapt to new pedagogy. Guidance should be given to students to develop social cohesion, peer tutoring and peer assessment among members [28]. Students' attitudes towards mathematics after intervention and their perception on cooperative learning supported this explanation.

In addition, students' attitudes towards mathematics after the instruction remains the same. This implies that students' attitudes towards mathematics might be not be changed within a short period. This finding contrasted with various existing studies [28]. In the study of Zengin and Tatar [33], an open-ended questionnaire was used to elicit students' attitudes towards the new learning environment. However, the instrument used in this study is a general Likert-scale of statements which measure students' attitudes towards mathematics. This instrument might not be sufficiently sensitive to measure students' perception of new learning model. A short period of instruction is another reason for this discrepancy.

\subsection{Limitations of the study}

This study has several limitations that need to be addressed in future. The duration of new instructional approach should be expanded to at least 2 weeks for students to learn the skills in groups. In order to verify the long-term effect of the intervention, a delayed post-test may be included in the future. Since the sample size of this study is small, it is preferable that more samples be investigated in future studies. Another weakness of the current study is the adoption of teacher-developed test. Future research may more profitably involve a standardized test. This could help avoid the possible instrumental bias and make the test results more robust. Furthermore, this instructional approach should be used in researching other mathematics topics such as solid geometry, other types of functions in further research. 


\section{Conclusion}

Investigation of students' difficulty in learning functions indicates that students' understanding of functions is often incomplete and confusing. This may affect their attainment in mathematics in the long term. In order to facilitate students' competence in mathematics, this study provides empirical evidence to support the instructional approach of cooperative learning, coupled with DMS, to teach inversely proportional function. This approach may solve the problem of students' overreliance on linearity and proportionality. Therefore, it is suggested that mathematics teachers use cooperative learning model with DMS to facilitate students' learning of difficult mathematics concepts. Instruction with an emphasis of the connection between mathematics and reality should be designed [39]. Guidance to brief students about the cooperative learning should be provided in advance.

\section{$6 \quad$ References}

[1] K. Larkin and N. Calder, "Mathematics education and mobile technologies,". Mathematics Education Research Journal, vol. 28, no. 1, pp. 1-7, 2016.

[2] Penglase, M. and S. Arnold, "The graphics calculator in mathematics education: A critical review of recent research," Mathematics education research journal, vol. 8, no. 1, pp. 5890, 1996. https://doi.org/10.1007/bf03355481

[3] V. Freiman, "Types of Technology in Mathematics Education," in Encyclopaedia of Mathematics Education, Dordrecht, Springer, 2014.

[4] S. Papadakis, M. Kalogiannakis and N. Zaranis, "The effectiveness of computer and tablet assisted intervention in early childhood students' understanding of numbers. An empirical study conducted in Greece.," Education and Information Technologies, vol. 23, no. 5, pp. 1849-1871, 2018. https://doi.org/10.1007/s10639-018-9693-7

[5] M. A. Al-Khateeb, "The Effect of Teaching Mathematical Problems Solving Through Using Mobile Learning on the Seventh Grade Students' Ability to Solve them in Jordan," International Journal of Interactive Mobile Technologies (iJIM), vol. 12, no. 3, pp. 178-191, 2018. https://doi.org/10.3991/ijim.v12i3.8713

[6] R. Wood and J. Ashfield, "The use of the interactive whiteboard for creative teaching and learning in literacy and mathematics: a case study," British journal of educational technology, vol. 39, no. 1, pp. 84-96, 2008. https://doi.org/10.1111/j.1467-8535.2007.00703.x

[7] NCTM, "Strategic Use of Technology in Teaching and Learning Mathematics," NCTM, 2015. [Online]. Available: https://www.nctm.org/Standards-and-Positions/PositionStatements/Strategic-Use-of-Technology-in-Teaching-and-Learning-Mathematics/. [Accessed 1 December 2019]. https://doi.org/10.5951/teacchilmath.22.8.0487

[8] "The Requirements of Basic Academic Attainments," DSEJ, 2016. [Online]. Available: http://www.dsej.gov.mo/crdc/edu/requirements-e.html. [Accessed 1 December 2019].

[9] E. Tatar, M. Okur and A. Tuna, "A study to determine learning difficulties in secondary mathematics education," Kastamonu Education Journal, vol. 16, no. 2, pp. 507-516, 2008.

[10] M. Mushipe and U. I. Ogbonnaya, "Geogebra and Grade 9 Learners' Achievement in Linear Functions," International Journal of Emerging Technologies in Learning (iJET), vol. 14, no. 8, pp. 206-219, 2019. https://doi.org/10.3991/ijet.v14i08.9581 
[11] A. Sfard, "On the dual nature of mathematical conceptions: Reflections on processes and objects as different sides of the same coin," Educational studies in mathematics, vol. 22, no. 1, pp. 1-36, 1991. https://doi.org/10.1007/bf00302715

[12] M. Sajka, "A secondary school student's understanding of the concept of function-A case study," Educational studies in mathematics, vol. 53, no. 3, pp. 229-254, 2003.

[13] A. A. Nistal, W. Van Dooren and L. Verschaffel, "What counts as a flexible representational choice? An evaluation of students' representational choices to solve linear function problems," Instructional Science, 40(6), 999-1019., vol. 40, no. 6, pp. 999-1019, 2012. https://doi.org/10.1007/s11251-011-9199-9

[14] D. De Bock, W. Van Dooren and L. Verschaffel, "Students' understanding of proportional, inverse proportional, and affine functions: two studies on the role of external representations," International Journal of Science and Mathematics Education, vol. 13, pp. 47-69, 2015. https://doi.org/10.1007/s10763-013-9475-z

[15] D. De Bock, W. Van Dooren and L. Verschaffel, "Students' overuse of linearity: An exploration in physics,". Research in Science Education, vol. 41, no. 3, pp. 389-412, 2011. https://doi.org/10.1007/s11165-010-9171-8

[16] E. Dubinsky and R. Wilson, "High school students' understanding of the function concept," The Journal of Mathematical Behavior, vol. 32, no. 1, pp. 83-101, 2013. https://doi. org/10.1016/j.jmathb.2012.12.001

[17] D. Velichová, "Interactive maths with GeoGebra," International Journal of Emerging Technologies in Learning (iJET), vol. 6, no. S1, pp. 31-35, 2011. https://doi.org/10.3991/ij et.v6is1.1620

[18] R. Pierce, K. Stacey, R. Wander and L. Ball, "The design of lessons using mathematics analysis software to support multiple representations in secondary school mathematics," Technology, Pedagogy and Education, vol. 20, no. 1, pp. 95-112, 2011. https://doi.org/10. 1080/1475939x.2010.534869

[19] C. Laborde, "The role and uses of technologies in mathematics classroom: Between challenge and modus vivendi," Canadian Journal of Science, Mathematics and Technology, vol. 7, no. 1, pp. 68-92, 2007. https://doi.org/10.1080/14926150709556721

[20] K. K. Chan, "Salient Beliefs of Mathematics Teachers Using Dynamic Geometry Software," EURASIA Journal of Mathematics, Science \& Technology Education., vol. 11, no. 1, pp. 139-148, 2015. https://doi.org/10.12973/eurasia.2015.1312a

[21] S. Bokosmaty, M. F. Mavilidi and F. Paas, "Making versus observing manipulations of geometric properties of triangles to learn geometry using dynamic geometry software," Computers \& Education, vol. 113, pp. 313-326, 2017. https://doi.org/10.1016 ji.compedu.2017.06.008

[22] K. K. Chan and S. W. Leung, "Dynamic geometry software improves mathematical achievement: systematic review and meta-analysis," Journal of Educational Computing Research, vol. 51, no. 3, pp. 311-325, 2014. https://doi.org/10.2190/ec.51.3.c

[23] Y. Zengin and E. Tatar, "The teaching of polar coordinates with dynamic mathematics software," International Journal of Mathematical Education in Science and Technology, vol. 46, no. 1, pp. 127-139, 2015. https://doi.org/10.1080/0020739x.2014.904529

[24] K. A. Bakar, A. F. M. Ayub, W. S. Luan and R. A. Tarmizi, "Exploring secondary school students' motivation using technologies in teaching and learning mathematics.," ProcediaSocial and Behavioral Sciences, vol. 2, no. 2, pp. 4650-4654, 2010. https://doi.org/10.10 16/j.sbspro.2010.03.744

[25] K. S. Choi, "Motivating students in learning mathematics with GeoGebra.," Annals. Computer Science Series, 8(2), 65-76, vol. 8, no. 2, pp. 65-76, 2010. 
[26] F. Olivero and O. Robutti, "Measuring in dynamic geometry environments as a tool for conjecturing and proving," International Journal of Computers for Mathematical Learning, vol. 12, no. 2, pp. 135-156, 2007. https://doi.org/10.1007/s10758-007-9115-1

[27] M. De Villiers, "Some pitfalls of dynamic geometry software," Learning and Teaching Mathematics, pp. 46-52, 2006.

[28] D. W. Johnson and R. T. Johnson, "An educational psychology success story: Social interdependence theory and cooperative learning," Educational researcher, vol. 38, no. 5, pp. 365-379, 2009. https://doi.org/10.3102/0013189x09339057

[29] R. E. Slavin, "Cooperative learning and academic achievement: Why does groupwork work?" Anales de Psicología/Annals of Psychology, vol. 30, no. 3, pp. 785-791, 2014. https://doi.org/10.6018/analesps.30.3.201201

[30] H. Pai, D. A. Sears and M. Yukiko, "Effects of small-group learning on transfer: A metaanalysis.," Educational Psychology Review, vol. 27, no. 1, pp. 79-102, 2015. https://doi. org/10.1007/s10648-014-9260-8

[31] E. Zakaria, L. C. Chin and M. Y. Daud, "The effects of cooperative learning on students' mathematics achievement and attitude towards mathematics," Journal of social sciences, vol. 6 , no. 2, pp. 272-275, 2010. https://doi.org/10.3844/jssp.2010.272.275

[32] A. Çetin, "Effects of simulation based cooperative learning on physics achievement, science process skills, attitudes towards physics and usage of interactive whiteboards," Kastamonu Education Journal, vol. 26, no. 1, pp. 57-65, 2018.

[33] B. Hariadi and T. Wurijanto, "Influence of Web Based Cooperative Learning Strategy and Achiever Motivation on Student Study Outcome," International Journal of Evaluation and Research in Education, vol. 5, no. 3, pp. 189-199, 2016. https://doi.org/10.11591/ijere.v5 i3.4538

[34] Y. Zengin and E. Tatar, "Integrating Dynamic Mathematics Software into Cooperative Learning Environments in Mathematics," Educational Technology \& Society, vol. 20, no. 2, pp. 74-88, 2017.

[35] C. Granberg and J. Olsson, "ICT-supported problem solving and collaborative creative reasoning: Exploring linear functions using dynamic mathematics software," The Journal of Mathematical Behavior, vol. 37, pp. 48-62, 2015. https://doi.org/10.1016/i.jmathb.2014.11. $\underline{001}$

[36] E. Marsden and C. J. Torgerson, "Single group, pre-and post-test research designs: Some methodological concerns," Oxford Review of Education, vol. 38, no. 5, pp. 583-616, 2012. https://doi.org/10.1080/03054985.2012.731208

[37] F. L. Wai, "DM_Lab Jianjie [Overview of DM_Lab]," 2002. [Online]. Available: https://sites.google.com/site/dmlab40/lab_intro. [Accessed 1 December 2019].

[38] M. Y. Li, (1983). Xing bie, nian ji, shu xue xue xi tai du, xing bie jiao se yu shu xue cheng jiu zhi guan xi [A relational study on gender, class, attitudes towards Mathematics, gender role and mathematics achievement], Taipei: National Chengchi University, 1983.

[39] G. M. Ghaith, "The relationship between cooperative learning, perception of social support, and academic achievement," System, vol. 30, no. 3, pp. 263-273, 2002. https://doi. org/10.1016/s0346-251x(02)00014-3

[40] S. Papadakis, M. Kalogiannakis and N. Zaranis, " Improving Mathematics Teaching in Kindergarten with Realistic Mathematical Education.," Early Childhood Education Journal, vol. 45, no. 3, pp. 369-378, 2016. https://doi.org/10.1007/s10643-015-0768-4 


\section{Authors}

Kan Kan Chan is an assistant professor in the Faculty of Education, University of Macau. Her main area of research is the use of technology in education. She engages in research topics such as dynamic geometry software in mathematics education, application of smart toys in early childhood classroom, the role of technology in classroom assessment and the visual analytics technology in instruction.

Yi Cheng Zhou is a graduate of Master of Education program in the Faculty of Education, University of Macau. He is a Mathematics school teacher in Macao.

Article submitted 2020-03-22. Resubmitted 2020-06-03. Final acceptance 2020-06-04. Final version published as submitted by the authors. 


\section{$8 \quad$ Appendix 1}

\section{Sample items of Pre-test}

1. Which of the following points is on the graph of function $y=\frac{1}{2} x+1$ ?
A $(2,1)$
B. $(-2,1)$
C. $(2,0)$
D. $(-2,0)$

2. When the car starts to drive, there is 40 liters of fuel in the fuel tank. If the fuel consumption is 5 liters per hour, the functional relationship between the remaining oil in the fuel tank y (liter) and the driving time $t$ (hour) should be represented by the image as shown in the figure below
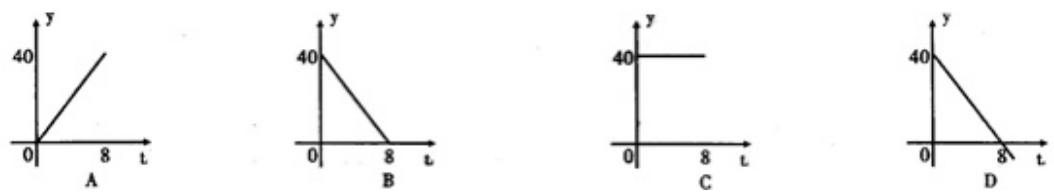

3. If the linear function intersects the negative of the y-axis, and the value of $y$ decreases with an increase of $x$, then $\mathrm{k}$ $0, \mathrm{~b}$ 0. (Fill in ">", "<" or "=")

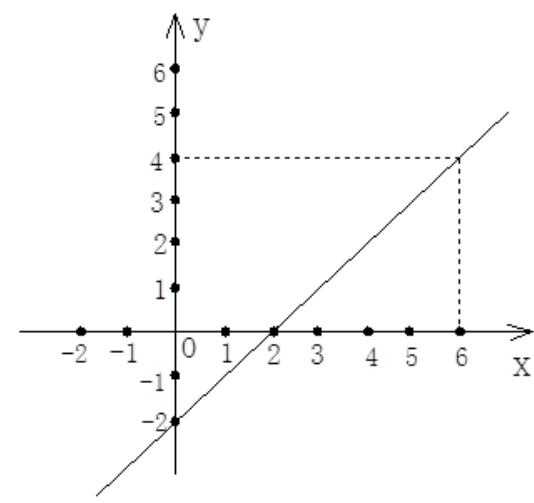

The image of the linear function is shown in the figure:

1) Find the formula of the linear function;

2) When $x=10$, what is the value of $y$ ?

3) When $y=12$, what is the value of $x$ ?

\section{$9 \quad$ Appendix 2}

\section{Sample items of post-test}


1. If Point A is on the hyperbola $y=\frac{k}{x}$, which of the following points is not on the hyperbola?
A. $(-2,-5)$
B. $(5,2)$
C. $(-5,2)$
D. $(10,1)$

2. The area of the triangle is $8 \mathrm{~cm}^{2}$, the image of the function between the height, $\mathrm{y}$ $(\mathrm{cm})$ and the base, $x(\mathrm{~cm})$ is

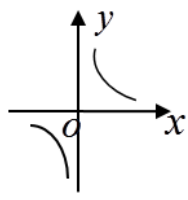

A.

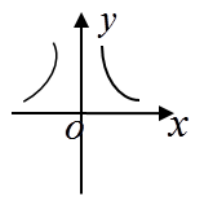

B.
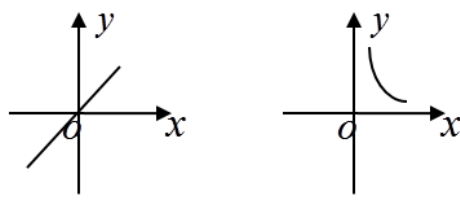

C.

D.

3. If Point $\mathrm{A}\left(\mathrm{x}_{1}, 1\right)$ and Point $\mathrm{B}\left(\mathrm{x}_{2}, 2\right)$ are on the hyperbola $y=\frac{k}{x}(k>0)$, then $\mathrm{x}_{1}$ $\mathrm{x}_{2}$ (fill in ">" or " $<$ ").

4. The image of the inverse proportional function is shown in the figure:

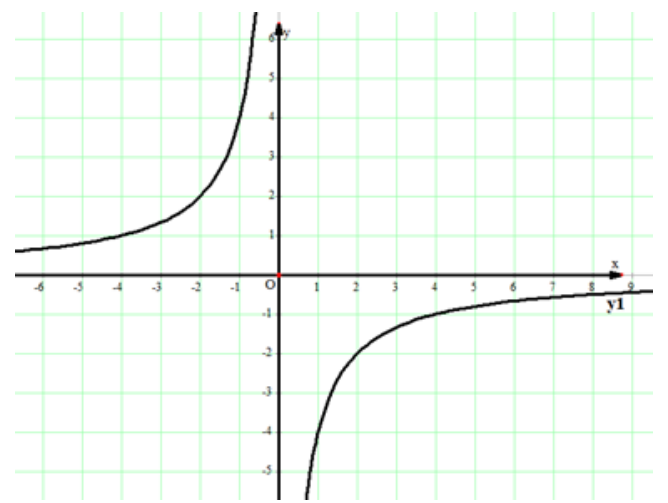

1) Find the analytical formula of the function;

2) When $x=16$, what is the value of $y$ ?

3 ) When $y=-20$, what is the value of $x$ ? 